\title{
Desenvolvimento de abacaxizeiros e qualidade de frutos sob diferentes métodos de controle de plantas daninhas
}

\author{
Pineapple development and fruit quality under different weed control methods \\ Desarrollo de la piña y calidad de la fruta bajo diferentes métodos de control de malezas
}

Recebido: 07/10/2021 | Revisado: 14/10/2021 | Aceito: 15/10/2021 | Publicado: 18/10/2021

Felipe de Tássio Gonçalves de Oliveira

ORCID: https://orcid.org/0000-0002-4931-0515 Instituto Capixaba de Pesquisa, Assistência Técnica e Extensão Rural, Brasil E-mail: felipe_dtassio@ hotmail.com

Valéria Pancieri Sallin

ORCID: https://orcid.org/0000-0002-4507-6610 Universidade Federal do Espírito Santo, Brasil E-mail: valeriapancieri@gmail.com

Basílio Cerri Neto

ORCID: https://orcid.org/0000-0002-5778-6185

Universidade Federal do Espírito Santo, Brasil

E-mail: basiliocerri@yahoo.com.br

Pietra de Souza Rodrigues

ORCID: https://orcid.org/0000-0002-3473-2432 Instituto Capixaba de Pesquisa, Assistência Técnica e Extensão Rural, Brasil

E-mail: pietra_sr@hotmail.com

Kayo Cesar Corrêa Lima

ORCID: https://orcid.org/0000-0001-9697-3613 Instituto Capixaba de Pesquisa, Assistência Técnica e Extensão Rural, Brasil E-mail: correakayocesar@outlook.com

Lúcio de Oliveira Arantes

ORCID: https://orcid.org/0000-0001-7266-6563 Instituto Capixaba de Pesquisa, Assistência Técnica e Extensão Rural, Brasil E-mail: lucio.arantes@incaper.es.gov.br

José Aires Ventura

ORCID: https://orcid.org/0000-0003-1422-1739 Instituto Capixaba de Pesquisa, Assistência Técnica e Extensão Rural, Brasil E-mail: ventura@incaper.es.gov.br

Edilson Romais Schmidt

ORCID: https://orcid.org/0000-0002-3457-7997

Universidade Federal do Espírito Santo, Brasil

E-mail: edilson.schmildt@ufes.br

José Altino Machado Filho

ORCID: https://orcid.org/0000-0001-7759-2479 Instituto Capixaba de Pesquisa, Assistência Técnica e Extensão Rural, Brasil E-mail: altino@incaper.es.gov.br

Sara Dousseau Arantes

ORCID: https://orcid.org/0000-0001-6202-4153 Instituto Capixaba de Pesquisa, Assistência Técnica e Extensão Rural, Brasil E-mail: sara.arantes@incaper.es.gov.br

\begin{abstract}
Resumo
Estratégias de manejo agrícola podem melhorar a produção, especialmente em regiões com condições ambientais críticas para o desenvolvimento de culturas agrícolas, porém, em plantas como o abacaxizeiro, ainda carece de pesquisa aplicada para otimizar a produção e a qualidade dos frutos. Este trabalho, teve como objetivo avaliar o desenvolvimento das plantas e a qualidade dos frutos do abacaxizeiro das cultivares Pérola e Vitória, submetidas a dois métodos de cultivo (com e sem mulching) e dois tipos de capina (química e manual). O experimento foi conduzido na Região Norte do Espírito Santo, em delineamento de blocos casualizados, esquema fatorial triplo $2 \times 2 \times 2$, onde avaliaram-se as cultivares Pérola e Vitória, inclusão ou não de mulching e realização da capina química ou manual. As plantas foram avaliadas quanto ao desenvolvimento vegetativo, teores de macro e micronutrientes e índice SPAD na folha D. Foram avaliadas a firmeza, massa, comprimento, diâmetro central e características físico-químicas. Nas condições edafoclimáticas do experimento, a cultivar Pérola teve crescimento mais rápido, porém teor de sólidos solúveis baixo $\left(12^{\circ}\right.$ Brix $)$ em relação à 'Vitória', apresentando-se indiferente em relação ao tipo de capina e mulching. Já a cv. Vitória produziu frutos com maior firmeza e teor de sólidos
\end{abstract}


solúveis de $16^{\circ}$ Brix, com importantes incrementos com o uso de mulching e capina manual, destacando-se nas características físico-químicas relacionado a qualidade dos frutos, o que leva a recomendar -se o uso destas técnicas para seu cultivo na região Litoral Norte do Espírito Santo.

Palavras-chave: Ananas comosu; Características físico-químicas; Cobertura plástica no solo.

\begin{abstract}
Agricultural management strategies can improve production, especially in regions with critical environmental conditions for the development of agricultural crops, however, in plants such as pineapple, applied research to optimize production and fruit quality is still lacking. This work aimed to evaluate plant development and fruit quality of pineapple from Pérola and Vitória cultivars, submitted to two cultivation methods (with and without mulching) and two types of weeding (chemical and manual). The experiment was carried out in the North Region of Espírito Santo, in a randomized block design, in a 2x2x2 triple factorial scheme, where the cultivars Pérola and Vitória were evaluated, including or not mulching and chemical or manual weeding. Plants were evaluated for vegetative development, macro and micronutrient contents and SPAD index in leaf D. Firmness, mass, length, central diameter and physicochemical characteristics were evaluated. Under the edaphoclimatic conditions of the experiment, the cultivar Pérola had faster growth, but low soluble solids content $\left(12^{\circ}\right.$ Brix $)$ compared to 'Vitória', being indifferent to the type of weeding and mulching. The cv. Vitória produced fruits with greater firmness and soluble solids content of $16^{\circ} \mathrm{Brix}$, with important increments with the use of mulching and manual weeding, standing out in the physicochemical characteristics related to the quality of the fruits, which leads to the recommendation for its use of these techniques for its cultivation in the North Coast region of Espírito Santo. Keywords: Ananas comosus; Physicochemical characteristics; Plastic covering in the soil.
\end{abstract}

\title{
Resumen
}

Las estrategias de manejo agrícola pueden mejorar la producción, especialmente en regiones con condiciones ambientales críticas para el desarrollo de cultivos agrícolas, sin embargo, en plantas como la piña, aún falta investigación aplicada para optimizar la producción y la calidad de la fruta. Este trabajo tuvo como objetivo evaluar el desarrollo vegetal y la calidad del fruto de la piña de los cultivares Pérola y Vitória, sometida a dos métodos de cultivo (con y sin mulching) y dos tipos de deshierbe (químico y manual). El experimento se realizó en

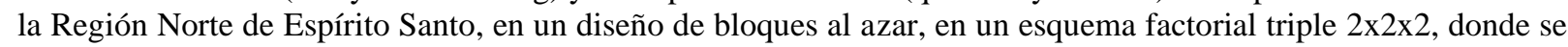
evaluaron los cultivares Pérola y Vitória, incluyendo o no mulching y deshierbe químico o manual. Se evaluó el desarrollo vegetativo de las plantas, el contenido de macro y micronutrientes y el índice SPAD en la hoja D. Se evaluaron la firmeza, masa, longitud, diámetro central y características fisicoquímicas. En las condiciones edafoclimáticas del experimento, el cultivar Pérola tuvo un crecimiento más rápido, pero bajo contenido de sólidos solubles $\left(12^{\circ}\right.$ Brix) en comparación con 'Vitória', indiferente al tipo de deshierbe y mulching. El cv. Vitória produjo frutos con mayor firmeza y contenido de sólidos solubles de $16^{\circ} \mathrm{Brix}$, con importantes incrementos con el uso de mulching y deshierbe manual, destacándose en las características fisicoquímicas relacionadas con la calidad de los frutos, lo que lleva a la recomendación para su uso de estas técnicas. para su cultivo en la región de la Costa Norte de Espírito Santo.

Palabras clave: Ananas comosus; Características fisicoquímicas; Cubierta plástica del suelo.

\section{Introdução}

O abacaxi, segunda fruta mais exportada mundialmente, tem uma produção global ascendente em 1,9\% ao ano, devendo acumular até 2028, cerca 31 milhões de toneladas (FAO, 2020). No Brasil o rendimento é baixo, cerca de 25 mil frutos $\mathrm{ha}^{-1}$ (IBGE, 2020), causado principalmente pela fusariose, pois o cultivo é baseado principalmente na cultivar Pérola, muito susceptível a esta doença (Reinhardt et al., 2018). Já existem cultivares resistentes a fusariose, como o 'Vitória', selecionado no Espírito Santo e lançada em 2006 (Ventura et al., 2009). Na época do seu lançamento, ações do governo capixaba incentivaram o cultivo do 'Vitória' e a sua adesão por alguns agricultores no município de Boa Esperança, proporcionou 45 mil frutos ha-1, entre 2006 a 2014 (IBGE, 2020). Contudo, embora utilizar cultivares resistentes aumente a produtividade, a recomendação e a consequente adesão pelos agricultores ainda é baixa, principalmente pela baixa disponibilidade de mudas para iniciar novos plantios.

Apesar dos esforços voltados para a resistência a doenças por meio do melhoramento genético, a interações entre o manejo agronômico e recursos edafoclimáticos ainda são pouco explorados quando se visa o rendimento e a qualidade de frutos de abacaxi, especialmente em locais como a Região Litoral Norte do Espírito Santo, em que ocorrem os menores índices pluviométricos do estado, com média mensal entre 3-50 mm e acumulo anual abaixo de $1.100 \mathrm{~mm}$ (Uliana et al., 2013) e 
geralmente acompanhados de temperaturas elevadas onde os valores máximos no decorrer do ano variam entre 26 a $41^{\circ} \mathrm{C}$ (Pezzopane et al., 2004), com intensa evapotranspiração, que levou a inclusão de parte dos municípios desta Região na área de abrangência da Superintendência de Desenvolvimento do Nordeste (SUDENE) pelo risco climático e índice de aridez (Araújo, 2019).

Outra característica marcante no cultivo do abacaxizeiro (Ananas comosus var. comosus) no Brasil é o baixo nível tecnológico adotado por grande parte dos agricultores (Reinhardt et al., 2018), onde muitos conduzem precariamente as lavouras, até mesmo limitando tratos culturais básicos, como capinas, irrigação e adubação. Nesse contexto tecnologias como a cobertura plástica no solo tem ganhado espaço e discussões, pois foi comprovado em diferentes culturas que além do aumento substancial no rendimento devido a conservação da água e de nutrientes no solo, há também a proteção contra a erosão e menor amplitude térmica, aumento de atividade microbiana, fotossíntese e maior controle sobre plantas invasoras (Sampaio; Araújo, 2001). As condições microclimáticas proporcionadas pela cobertura com filme plástico promovem o desempenho das plantas no estabelecimento em campo, expressas por elevadas taxas de crescimento (O'loughlin; Finnan; Mcdonnell, 2017), acúmulo de massa seca foliar, área foliar e eficiência fotossintética (Rebolledo Martinez et al., 2005), que culminam em acréscimos na produtividade e na qualidade dos frutos (Silva et al., 2020).

Em abacaxizeiro, especificadamente, a prática da cobertura do solo possibilita melhor controle das plantas daninhas, manejo, imprescindível no ciclo da cultura pois a presença de plantas que competem por água, luz e nutrientes retardam o crescimento do abacaxizeiro (Souza et al., 2009). Dentre os principais tratamentos no manejo de plantas daninhas na abacaxicultura, Model e Fravetto (2010) descrevem a capina manual com enxada, cobertura morta, polietileno preto nas linhas de plantio e capina química com herbicida. Se por um lado, o controle químico mostra-se $22 \%$ mais econômico que o método da capina (Model et al., 2010) por outro, questionamentos a respeito dessa prática têm sido feitos por questões ambientais e econômicas.

Diante do exposto, notam-se vantagens da adoção de coberturas plásticas para o abacaxizeiro e do controle de plantas daninhas. Entretanto, há necessidade de um estudo que relacione a qualidade da produção a essas práticas agrícolas, aliando-as para que haja atendimento das demandas de quantidade e qualidade dos frutos, focando nos cultivares resistentes a fusariose, mas comparando-os com a cv. Pérola, visando aumentar a recomendação e a adesão pelos agricultores. O objetivo neste trabalho foi avaliar o desenvolvimento das plantas e a qualidade dos frutos do abacaxizeiro cultivares Pérola e Vitória, submetidas a dois métodos de cultivo (com e sem mulching) e dois tipos de capina (química e manual).

\section{Metodologia}

O experimento em campo foi conduzido entre maio de 2017 a outubro de 2018 na Fazenda Experimental de Sooretama (FES), do Instituto Capixaba de Pesquisa Assistência Técnica e Extensão Rural (INCAPER), situado na região Litoral Norte do Espírito Santo, no município de Sooretama, localizada nas coordenadas geográficas de 19¹1’30" de latitude sul e $40^{\circ} 05^{\prime} 46^{\prime \prime}$ de longitude oeste. O clima da região é classificado como Aw - tropical úmido, com inverno seco e verão quente e úmido, de acordo com a classificação de Köppen (Alvares et al., 2013).

Foram utilizadas mudas do tipo de filhote (com aproximadamente $30 \mathrm{~cm}$ e $150 \mathrm{~g}$ ) de abacaxizeiro da cultivar Vitória provenientes da Fazenda Experimental Bananal do Norte (FEBN), do Incaper, no distrito de Pacotuba- Cachoeiro de Itapemirim, e da cultivar Pérola obtidas de lavouras comerciais de Marataízes.

O delineamento experimental adotado consistiu em bloco casualizados esquema fatorial $2 \times 2 \times 2$ em quatro repetições, sendo o primeiro fator constituído pelas cultivares Pérola e Vitória, o segundo pela inclusão ou não de mulching na linha de plantio e o terceiro pela realização da capina química e capina manual na entrelinha de plantio. Cada parcela experimental foi 
composta por 72 plantas dispostas em três fileiras duplas, das quais apenas as 20 plantas centrais foram consideradas para as avaliações.

Antes do preparo do solo foram coletadas amostras de solo na faixa de 0-20 $\mathrm{cm}$ de profundidade, e encaminhadas para o laboratório de análise do solo do INCAPER. Os resultados (Tabela 1) foram interpretados e feita a correção de fertilidade do solo conforme Prezotti et al. (2007). No decorrer de condução das plantas, o suprimento de nitrogênio e potássio foi ajustado para a cultura, de forma líquida, através da fertirrigação localizada e com aplicação de 16 doses iguais em intervalos de tempo decrescente, conforme Souza e Almeida (2002).

Tabela 1. Valores dos parâmetros de fertilidade do solo da área de implantação do experimento.

\begin{tabular}{|c|c|c|c|c|c|c|c|c|c|c|c|c|c|c|}
\hline $\mathbf{H}$ & & $\mathbf{a}$ & $\mathbf{a}$ & $\mathbf{g}$ & 1 & $+\mathrm{Al}$ & & $\%$ & $\%$ & $\mathbf{n}$ & e & $\mathbf{n}$ & $\mathbf{u}$ & \\
\hline${ }_{2} \mathrm{O}$ & & $\mathrm{mg} \mathrm{dm}^{-3}$ & \multicolumn{5}{|c|}{ cmolc dm ${ }^{-3}$} & & $\%$ & \multicolumn{4}{|c|}{$\mathrm{mg} \mathrm{dm}{ }^{-3}$} & \\
\hline 6 &, 4 & 75 & ,3 & ,6 &, 1 & ,3 & ,6 & 9,1 & ,5 & 2,3 & 5,5 & 6,7 &, 5 & ,7 \\
\hline
\end{tabular}

Fonte: Autores.

Para os tratamentos com mulching na linha de plantio foram levantados canteiros com 20 a 30 cm de altura e após a distribuição das mangueiras dos sistemas de irrigação, foi disposto sobre a estrutura, mulching plástico preto de 25 micras de espessura. Feito isso, procedeu-se a implantação das mudas em fileira dupla com espaçamentos de 0,9m x 0,4m x 0,30 m. A irrigação foi realizada pelo sistema de gotejamento com aspersores de vazão de $2 \mathrm{~L} \mathrm{~h}^{-1}$, e turno de rega a cada 3 dias. A indução floral artificial foi realizada aos 11 meses após o plantio, com o uso de Ethephon (ácido 2-cloroetil-fosfônico) a 100 mg L L ${ }^{-1}$, aplicando-se $30 \mathrm{~mL}$ da solução sobre a roseta foliar, por planta, conforme Kist et al. (2011), entre 8 e 9 h do dia.

$\mathrm{O}$ controle das plantas daninhas foi realizado mediante a densidade destas nas entrelinhas, realizando-se durante o ciclo, nove capinas manuais com enxada e cinco aplicações do herbicida que possui como ingrediente ativo Diurom na dose de $5,0 \mathrm{ml} \mathrm{L}{ }^{-1}$ de produto concentrado em água, aplicados com pulverizador costal equipado com protetor tipo "chapéu Napoleão" afim de evitar deriva do herbicida. A capina foi realizada sempre que necessário e pelo mesmo trabalhador rural. A data e o tempo gasto em cada parcela foi registrado, sendo o valor expresso em $\mathrm{h} \mathrm{m}^{2}$.

No sétimo e décimo mês após o plantio, foram avaliadas a altura $(\mathrm{cm})$ e o vigor das plantas úteis, para a primeira utilizou-se régua milimétrica e para o vigor das plantas, a classificação visual baseada na coloração, com uma escala de notas de 1 a 3, sendo $1=$ amarela, 2 = pouco amarela e 3= verde. Na indução floral foram coletadas dez folhas " $D$ " das plantas na área útil de cada parcela, para avaliação do índice SPAD (Soil Plant Analyzer Develop) através do clorofilômetro portátil (SPAD-502 Minolta Corp., Ramsey, Nova Jersey, EUA). As leituras foram realizadas entre as 8 e 9 horas da manhã nos terços médios das folhas considerando sua face abaxial. Após a avaliação as folhas foram encaminhadas para secagem em estufa de circulação forçada de ar a $65^{\circ} \mathrm{C}$ durante 15 dias e após isso, as amostras foram moídas em moinho tipo Willey, acondicionadas em sacos de papel e enviadas para o Laboratório Agronômico Labominas@, para quantificação dos teores de macro e micronutrientes no tecido foliar.

Os frutos foram colhidos apresentando de 11 a $25 \%$ de sua casca amarelo alaranjada (estádio "pintado"), conforme a Instrução Normativa voltada para abacaxi de polpa branca (MAPA, 2017). Em laboratório, estes frutos foram avaliados quanto a firmeza $(\mathrm{KgF})$, conforme a resistência da casca a penetração através da aplicação de força de um dinamômetro digital de força tipo Impac $®$ modelo IP-90DI com ponta cilíndrica de $8 \mathrm{~mm}$ em 4 pontos situados na região equatorial dos frutos, o peso do fruto sem coroa $(\mathrm{g})$ e peso da coroa $(\mathrm{g})$ foram realizados por meio da pesagem individual em balança semi-analítica 
Shimadzu BL3200H. Já o comprimento do fruto sem coroa $(\mathrm{cm})$ foi feito através de medição direta com régua graduada enquanto a circunferência do fruto foi obtida com uso fita métrica. Para as análises físico-químicas, os frutos foram descascados e triturados em centrífuga Juicer 700W Philips Walita BR, a fim de obter o suco homogêneo para as análises de rendimento e qualidade da polpa.

O rendimento de polpa (\%) foi obtido através da relação entre volume/massa e os valores foram convertidos em percentagem. Na medição do volume de suco extraído no fruto individual, foi realizada a leitura em proveta graduada $(\mathrm{mL})$, em seguida, realizou-se as medidas de vitamina C e com base nas normas do Instituto Adolfo Lutz (IAL, 2008) determinou-se a acidez titulável (\% de ácido cítrico), sólidos solúveis ( ${ }^{\circ}$ Brix) através de leituras em refratômetro digital Schmidt Haensch ATR-BRß com compensação automática de temperatura na faixa de 5 a $50^{\circ} \mathrm{C}$, razão entre Sólidos solúveis e acidez titulável (SS/AT) através da divisão dos valores encontrados dos sólidos solúveis.

Todos os dados avaliados foram submetidos a análises de variância com a comparação de médias pelo teste de Tukey a 5\% de probabilidade no programa estatístico $\operatorname{Sisvar}^{\circledR}$ (Ferreira, 2011).

\section{Resultados e Discussão}

O mulching reduziu o tempo de capina combinado com a capina manual foi mais eficiente que o cultivo apenas com controle químico (Figura 1). O cultivo no mulching quando combinado com controle químico praticamente não foi necessário efetuar o manejo das plantas daninhas. O trabalhador rural gastou mais tempo na capina da cultivar Pérola, certamente devido aos espinhos que ela possui.

Figura 1. Tempo de capina do abacaxizeiro das cultivares Pérola e Vitória, cultivadas em diferentes sistemas produtivos quanto ao manejo de plantas daninhas.

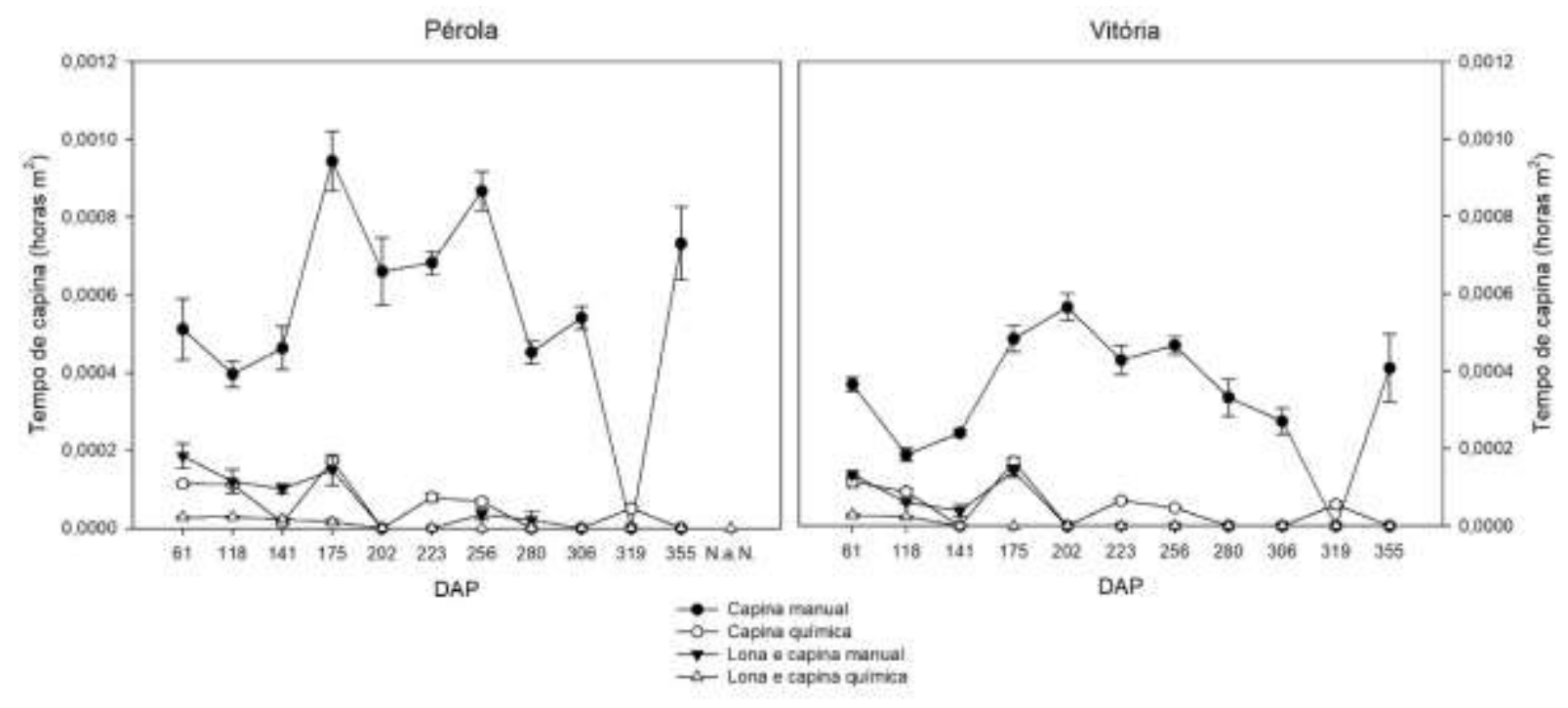

Fonte: Autores.

O tipo de capina teve efeito diferenciado entre as cultivares, em relação ao desenvolvimento vegetativo das plantas, sendo a resposta apenas afetada pelo genótipo e pela presença do mulching. O cultivo de abacaxi sobre mulching afeta significativamente o desenvolvimento vegetativo inicial de plantas da cv. Vitória, enquanto para a cv. Pérola não promoveu alterações na altura e vigor da planta (Tabela 1). Na fase inicial a diferença de altura para o 'Vitória' em relação a cobertura plástica foi mais expressiva, as plantas cultivadas com a cobertura foram em torno de 40,5\% maior no comprimento aos 7 meses e aproximadamente $31 \%$ no $10^{\circ}$ mês (Tabela 1 ). 
Foi observado maior desenvolvimento vegetativo da 'Pérola' em relação ao 'Vitória' independente do uso de mulching nos primeiros sete meses de desenvolvimento das plantas e equivalente em ambas as cultivares aos dez meses com o uso da cobertura plástica. Esta constatação revela que na cultivar Vitória, o crescimento inicial é mais lento em relação ao 'Pérola', pela própria característica genética das plantas e que a manutenção de um microclima na base da muda pode estimular as fases iniciais do desenvolvimento vegetativo com expressão do seu potencial genético, tornando a cultivar mais competitiva, pois uma vez que o crescimento rápido leva à antecipação da colheita dos frutos e retorno do investimento. Na cv. Vitória observou-se uma resposta significativa da altura $(\mathrm{p}<0,05)$ no sistema de condução com mulching (Tabela 1).

Tabela 1. Desenvolvimento vegetativo dos abacaxizeiros cultivares Pérola e Vitória, aos 7 e 10 meses após o plantio, cultivados em sistema com e sem mulching. *Médias com mesmas letras minúsculas na coluna e mesmas letras maiúsculas na linha não diferem estatisticamente pelo teste Tukey a $(\mathrm{p}>0,05)$.

\begin{tabular}{|c|c|c|c|c|c|}
\hline \multirow{4}{*}{ ltivar } & \multicolumn{5}{|c|}{ ALTURA DA PLANTA (cm) } \\
\hline & \multirow{3}{*}{$\mathrm{Cu}$} & \multicolumn{2}{|l|}{7 meses } & \multicolumn{2}{|l|}{10 meses } \\
\hline & & Sem & Com & Sem & Com \\
\hline & & mulching & mulching & mulching & mulching \\
\hline & Pér & & & & \\
\hline \multirow[t]{2}{*}{ ola } & & $64,37 \mathrm{aA}$ & $68,37 \mathrm{aA}$ & $90,50 \mathrm{aA}$ & $93,12 \mathrm{aA}$ \\
\hline & Vit & & & & \\
\hline \multirow[t]{2}{*}{ ória } & & $43,25 \mathrm{bB}$ & $60,75 \mathrm{bA}$ & $70,75 \mathrm{bB}$ & $92,62 \mathrm{aA}$ \\
\hline & $\mathrm{CV}$ & & & & \\
\hline \multirow[t]{3}{*}{$\%$} & & 11,53 & & 6,65 & \\
\hline & VIG & & & & \\
\hline & Pér & & & & \\
\hline \multirow[t]{2}{*}{ ola } & & $2,0 \mathrm{aA}$ & $2,0 \mathrm{aA}$ & $2,0 \mathrm{aA}$ & $2,0 \mathrm{aA}$ \\
\hline & Vit & & & & \\
\hline \multirow[t]{2}{*}{ ória } & & $1,12 \mathrm{bB}$ & $2,0 \mathrm{aA}$ & $1,87 \mathrm{aA}$ & $2,0 \mathrm{aA}$ \\
\hline & $\mathrm{CV}$ & & & & \\
\hline$\%$ & & 9,92 & & 8,98 & \\
\hline
\end{tabular}

Fonte: Autores.

O crescimento lento da cv. Vitória também foi observado em estudos com mudas micropropagadas cultivadas em campo, que investigaram o comportamento da cultura sem compara-la ao Pérola. Em suas investigações, Cardoso et al. (2013) associaram o lento desenvolvimento das plantas com o menor tamanho das mudas micropropagadas, agravado por condições edafoclimáticas adversas para a cultura no semiárido mineiro, onde há ocorrência de elevado déficit de pressão de vapor e temperatura elevada, mesmo nas plantas mantidas irrigadas por aspersão. Já Silva et al. (2012), levantaram a hipótese que na fase inicial as mudas micropropagadas possuem baixa capacidade em aproveitar o nitrogênio aplicado na fertilização. Mudas micropropagadas são mais sensíveis e possuem juvenilidade maior, mesmo se forem corretamente aclimatizadas, tornando-se importante proceder ao enviveiramento antes de leva-las para campo (Caetano; Ventura, 2018). Por outro lado, possuem sistema radicular desenvolvido, ao contrário das mudas do tipo filhote, sem raízes, que utilizamos neste experimento. Portanto, além do mulching, o tipo de muda utilizada e estratégias de manejo nutricional e hídrico também devem ser considerados para induzir o desenvolvimento inicial das plantas.

A diferença entre as cultivares é destacada pela característica da cv. Vitória investir a maior parte da energia de seu metabolismo na formação de folhas mais espessas, com parede celular mais rígida (Aquije et al., 2010) do que na multiplicação e alongamento celular, que levaria ao aumento no comprimento. Além disso, na fase inicial em condições onde é 
necessária adaptação, o abacaxizeiro Vitória tende a alocar mais massa seca nas raízes em detrimento da parte aérea, levando ao menor desenvolvimento do dossel e área foliar (Couto et al, 2016).

Ressalta-se também que a inclusão de cobertura plástica no cultivo do abacaxizeiro 'Vitória' ganha mais importância no estabelecimento do cultivo na Região Litoral Norte do Espírito Santo, onde a temperatura média é elevada, os solos são pobres em nutrientes e susceptível a elevado déficit hídrico (Mello et al., 2012). Presume-se que a adoção do mulching contribui para o crescimento das plantas, por moderar o regime da umidade do solo e atenuar flutuações da temperatura, refletindo no desenvolvimento radicular e uso eficiente da água e nutrientes, contribuindo para a resiliência ao clima, conforme descrito por Acharya, Bandyopadhyay e Hati (2018), sobre o uso de cobertura do solo na agricultura.

Os ganhos em vigor obtidos nesta pesquisa relacionam-se fortemente com o índice SPAD que correlaciona-se com teor de clorofila das folhas, sendo maior para o 'Vitória', onde a resposta de vigor e índice SPAD crescem proporcionalmente quando as plantas são submetidas ao cultivo com mulching (Tabela 2). O uso da cobertura plástica no solo proporcionou maiores valores de SPAD em ambos os cultivares. Embora o índice SPAD seja considerado uma ferramenta eficaz para as predições de estresses ambientais, o único estudo que avaliou SPAD em folhas de abacaxi foi o de Leonardo et al. (2013), que ao conduzirem em condições de campo, plantas de abacaxizeiro 'Vitória' provenientes de propagação in vitro, variando as fontes de nitrogênio (orgânica e mineral) no decorrer do ciclo, identificaram o valor de 55,26 quando as plantas completaram 13 meses após o plantio. Essa diferença provavelmente se deu pela idade das plantas na avaliação, que ainda seriam submetidas à indução floral, com todo o metabolismo ainda direcionado ao desenvolvimento vegetativo.

Tabela 2. Índice SPAD das folhas D em abacaxizeiros das cultivares Pérola e Vitória, aos 11 meses após o plantio (momento da indução floral), cultivados em sistema com e sem mulching e submetidos à capinas manual e química para o controle de plantas daninhas. *Médias com mesmas letras minúsculas na coluna e mesmas letras maiúsculas na linha não diferem estatisticamente pelo teste Tukey ( $p>0,05)$.

\begin{tabular}{lll}
\hline \multirow{2}{*}{ Cultivar } & Índice SPAD & \\
\cline { 2 - 3 } & Sem Mulching & Com Mulching \\
\hline Pérola & $71,61 \mathrm{aB}$ & $80,28 \mathrm{aA}$ \\
Vitória & $65,23 \mathrm{bB}$ & $72,88 \mathrm{bA}$ \\
\hline & Capina manual & Capina química \\
\hline Pérola & $76,71 \mathrm{aA}$ & $75,18 \mathrm{aA}$ \\
Vitória & $73,66 \mathrm{aA}$ & $64,45 \mathrm{bB}$ \\
\hline CV \% & 7,21 & \\
\hline
\end{tabular}

Fonte: Autores.

Ao comparar o índice SPAD no manejo da capina, percebe-se que o cultivar Vitória teve redução nos valores em função do controle químico, com redução de 12,5 \% em relação a capina manual. O fato pode estar associado a uma sensibilidade do 'Vitória' com a exposição ao Diuron, podendo apresentar fitotoxidez, marcada pela queda do nível de clorofila. Danos no aparelho fotossintético do abacaxizeiro foram descritos por Catunda et al. (2005) ao realizarem aplicações de Diuron (produto utilizado neste experimento) especialmente em adição de Paraquat, no entanto os autores relatam que as perdas foram reversíveis no espaço de 5 dias, mostrando resiliência da planta, que não chegou manifestar sintomas visíveis.

A análise de teores de nutrientes do tecido foliar do abacaxizeiro evidenciou que a variável esteve sob influência apenas do fator genético, enquanto as práticas de cobertura do solo e manejo de plantas daninhas apresentaram diferença significativa apenas para o teor de boro. Os maiores teores de nitrogênio, manganês e ferro justificam os valores superiores de 
SPAD e a altura da planta para a cultivar Pérola, uma vez que ambos constituem compostos envolvidos na fase fotoquímica da fotossíntese, os quais geram de ATP e NADPH, que posteriormente atuam na incorporação de carbono e produção de açúcares utilizados no metabolismo vegetal (Taiz et al., 2017).

Tabela 3. Teores de nutrientes das folhas " $D$ " em abacaxizeiros das cultivares Pérola e Vitória, aos 11 meses após o plantio (momento da indução floral), cultivados em sistema com e sem mulching e submetidos à capinas manual e química para o controle de plantas daninhas. *Médias com letras memas minúsculas na coluna e mesmas letras maiúsculas na linha não diferem estatisticamente pelo teste Tukey $(\mathrm{p}>0,05)$.

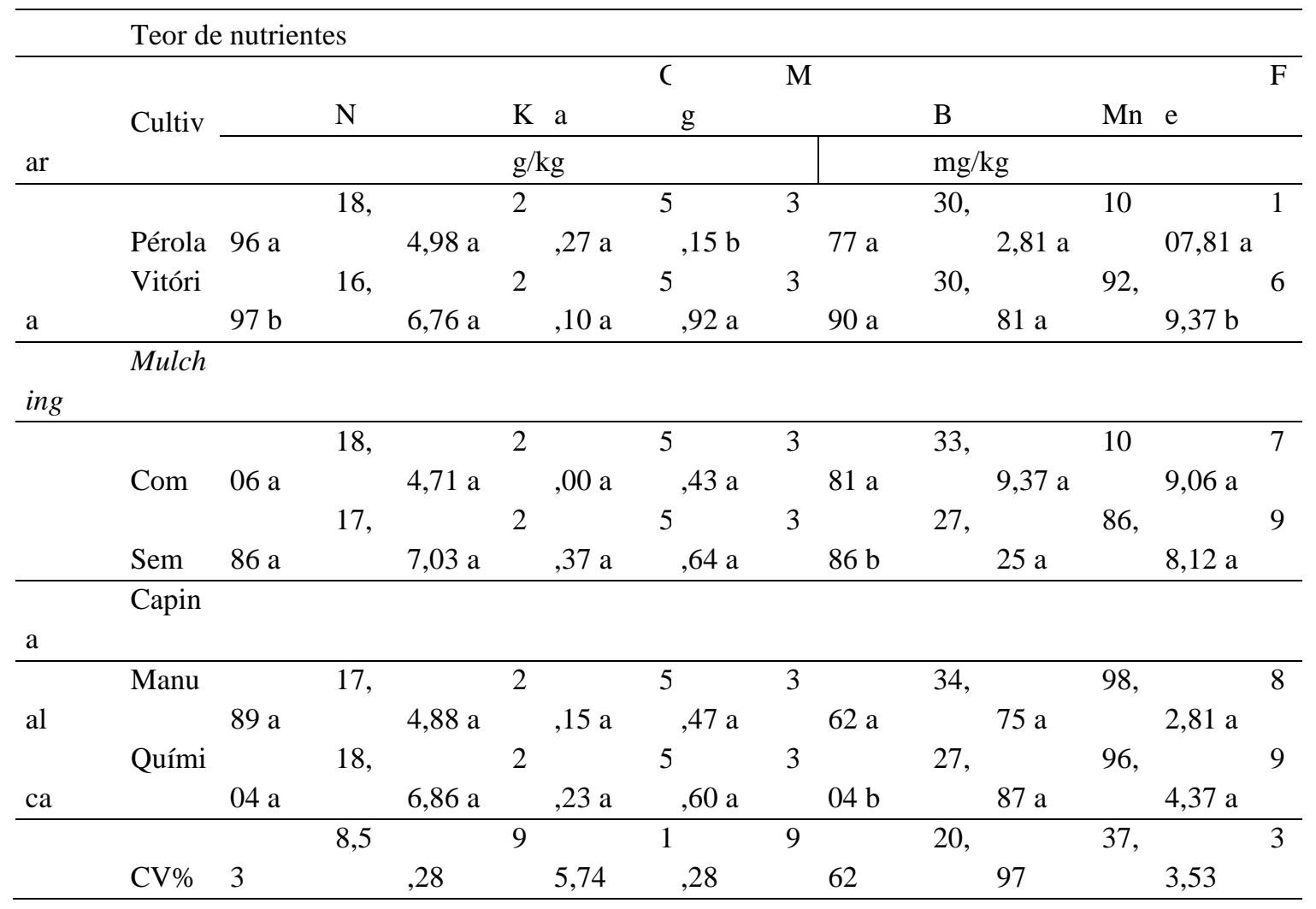

Fonte: Autores.

Os valores de nitrogênio da folha "D" ultrapassaram levemente a faixa entre 15 a $17 \mathrm{~g} \mathrm{~kg}^{-1}$ proposta por Malézieux e Bartholomew (2003) para abacaxizeiros, contudo a adição obtida não foi prejudicial para as plantas, ao contrário, a manutenção do nitrogênio no tecido foliar é importante em virtude das funções no metabolismo ácido das crassuláceas, e também por estar presente na formação de compostos fundamentais para o abacaxizeiro, desde aminoácidos, proteínas e clorofilas (Vieira et al., 2010).

De modo geral o incremento de cálcio não foi favorecido em nenhuma das condições de tratamento e o valor obtido ficou abaixo da faixa de suficiência ( 8 a $12 \mathrm{~g} / \mathrm{kg}$ ) proposta por Prezotti et al. (2007). Verifica-se que além de Ca, os valores de K também foram próximos do exposto por (Venâncio et al., 2017) na cultivar Vitória, com lâmina de irrigação de 655,18 mm, e no mesmo trabalho, o volume de 446,77 mm provocou o acúmulo de 16,0;12,0 e 4,0 g/kg de Ca, $\mathrm{K}$ e $\mathrm{Mg}$ respectivamente. Em solos da Região Litoral Norte do Espírito Santo, assim como em grande parte do Brasil, possuem acidez alta, disponibilidade baixa fertilidade e lixiviação intensa (Guarçoni et al., 2019), o que associado a abordagens inadequadas na adubação, com subparcelamento das doses na fertirrigação e as demandas de nutrientes da cultura, gera déficits intensos que podem ser evidenciados na produção, mas sobretudo no tecido foliar, como é o caso do Ca. Há também o efeito da fertirrigação aplicada, pois em locais onde há baixa saturação de $\mathrm{Ca}$ e $\mathrm{Mg}$, a prática do parcelamento da adubação potássica 
torna o $\mathrm{K}^{+}$predominante, deslocando os cátions $\mathrm{Ca}^{+2}$ e $\mathrm{Mg}^{+2}$ com maior energia de adsorção (Malavolta, 1982; Veloso et al., 2001; Venâncio et al., 2017).

O teor de ferro extraída pelas plantas evidenciou que apenas o 'Pérola' ficou na faixa ideal de $100-200 \mathrm{mg} \mathrm{kg}^{-1}$ (Prezotti et al. 2007), e o pior resultado dentre os tratamentos foi obtido na cv. Vitória, que pode ser uma desvantagem uma vez que este micronutriente é fundamental na síntese de complexos constituídos por clorofila, e constituinte das enzimas que realizam transferências de elétrons (Taiz et al., 2017), o que contribui para a hipótese que o crescimento reduzido desta cultivar em relação ao 'Pérola', além da influência edafoclimática, tem também a nutricional, pois se a transferência de elétrons é reduzida, a incorporação de carbono e produção de energia também é afetada.

Já para Boro, os valores foram abaixo da faixa proposta por Prezotti et al. (2007) apenas quando o abacaxizeiro foi submetido a capina química sem o uso de mulching, mas os valores estão dentro da faixa encontrada para o abacaxi no Brasil. Nos frutos deste estudo, não foram identificadas alterações decorrentes da deficiência de boro, sendo os principais sintomas descritos por Siebeneichler et al. (2008), como anomalias em formato e tamanho e presença de rachaduras e tecidos corticosos entre os frutilhos, ambas características não aceitáveis pelo mercado consumidor.

Os valores de manganês obtido para a cultura embora não tenham tido diferença significativa contradiz alguns relatos em outras culturas em que foi utilizado o filme plástico preto como cobertura, com relatos da redução deste micronutriente no tecido foliar (Mógor \& Câmara, 2009). Os valores encontrados para Mn encontram-se na faixa de 50-200 mg kg-1 proposta para a cultura (Malavolta; Vitti; Oliveira, 1997; Prezotti et al., 2007). A relação K/Mg reforça a importância da calagem no pré-plantio de abacaxi, principalmente para o 'Vitória' (Tabela 4), com valores próximos ao tratamento testemunha de trabalho de Rodrigues et al. (2013) os quais destacam que a ausência de correção promoveu a absorção de $\mathrm{K}$ em detrimento ao $\mathrm{Mg}$ devido à baixa concentração deste último.

Diferenças significativas também ocorreram na relação K/Mn quando utilizado o mulching, em que a relação foi menor, indicando maior teor de $\mathrm{Mn}$, no entanto, resultados científicos para a cultura não mencionam valores deste elemento $\mathrm{e}$ as consequências dessa relação. Maia et al. (2020) descrevem apenas que estes nutrientes tem relação de antagonismo, já para a relação $\mathrm{Ca} / \mathrm{Mg}$, os mesmos autores propõem variação de 1:1 a 2:1 devido as necessidades específicas que as cultivares trazem em si.

Pegoraro et al. (2014) demonstraram que o abacaxizeiro de modo especial, o 'Vitória', possui uma alta demanda de magnésio e que a absorção de cálcio e magnésio é afetada pela disponibilidade no solo e fornecimento pela fertilização. Por fim, o nota-se também na tabela acima uma redução de $31 \%$ na relação $\mathrm{Ca} / \mathrm{Mn}$ quando adotado o cultivo sob o mulching, no entanto os valores ideais dessa relação para o abacaxi ainda são pouco conhecidos, bem como a cobertura do solo pode interferir na absorção de ambos os elementos. Barbosa et al. (2013) descreve que o manganês possui interação antagônica com $\mathrm{Ca}$ e outros cátions ( $\mathrm{Zn}, \mathrm{Mg}$ e $\mathrm{Fe}$ ) e a semelhança em termos de raio iônico entre eles favorece a absorção de um em diminuição de outro. 
Tabela 4. Relação entre nutrientes da folha " $D$ " de abacaxizeiros Pérola e Vitória e diferentes métodos para controle de plantas daninhas. *Médias seguidas de mesmas letras minúsculas na coluna, na comparação entre os níveis dos fatores, não diferem estatisticamente pelo teste Tukey $(\mathrm{p}>0,05)$.

\begin{tabular}{|c|c|c|c|c|c|c|c|c|c|c|}
\hline \multicolumn{11}{|c|}{ Relação entre os nutrientes } \\
\hline \multirow[b]{2}{*}{ Cultivar } & \multirow[b]{2}{*}{$\mathrm{K}$} & \multicolumn{2}{|l|}{$\mathrm{N} /$} & \multirow[t]{2}{*}{$\mathrm{K} / \mathrm{M}$} & & \multirow[t]{2}{*}{$\mathrm{K} / \mathrm{M}$} & \multirow{2}{*}{\multicolumn{2}{|c|}{$\mathrm{Ca} /$}} & \multirow[b]{2}{*}{$\mathrm{Mn}$} & \multirow[t]{2}{*}{$\mathrm{Ca} /$} \\
\hline & & & $\mathrm{g}$ & & $\mathrm{n}$ & & & & & \\
\hline & & 0,7 & & 8,11 & & 0,27 & & 1,67 & & 0,05 \\
\hline \multirow[t]{2}{*}{ Pérola } & $7 \mathrm{a}$ & & $\mathrm{a}$ & & $\mathrm{a}$ & & a & & $6 a$ & \\
\hline & & 0,6 & & 6,81 & & 0,33 & & 1,29 & & 0,06 \\
\hline Vitória & $4 \mathrm{~b}$ & & $\mathrm{~b}$ & & $\mathrm{a}$ & & $\mathrm{b}$ & & $2 \mathrm{a}$ & \\
\hline \multicolumn{11}{|l|}{ Mulching } \\
\hline & & 0,7 & & 7,30 & & 0,24 & & 1,48 & & 0,04 \\
\hline \multirow[t]{2}{*}{ Com } & $4 \mathrm{a}$ & & $\mathrm{a}$ & & $\mathrm{b}$ & & $\mathrm{a}$ & & $8 \mathrm{~b}$ & \\
\hline & & 0,6 & & 7,61 & & 0,37 & & 1,49 & & 0,07 \\
\hline Sem & $7 \mathrm{a}$ & & $\mathrm{a}$ & & $\mathrm{a}$ & & $\mathrm{a}$ & & $0 \mathrm{a}$ & \\
\hline \multicolumn{11}{|l|}{ Capina } \\
\hline & & 0,6 & & 7,82 & & 0,32 & & 1,46 & & 0,06 \\
\hline \multirow[t]{2}{*}{ Manual } & $7 \mathrm{a}$ & & $\mathrm{a}$ & & $\mathrm{a}$ & & $\mathrm{a}$ & & $1 \mathrm{a}$ & \\
\hline & & 0,7 & & 7,09 & & 0,28 & & 1,51 & & 0,05 \\
\hline \multirow[t]{2}{*}{ Química } & $4 \mathrm{a}$ & & $\mathrm{a}$ & & $\mathrm{a}$ & & $\mathrm{a}$ & & $7 \mathrm{a}$ & \\
\hline & & 18 & & 17,5 & & 44,7 & & 13,0 & & 39,8 \\
\hline CV\% & 79 & & 6 & & 2 & & 6 & & 5 & \\
\hline
\end{tabular}

Fonte: Autores.

Maia et al. (2020) evidenciam que diferenças entre teor de nutrientes no tecido de abacaxi são comuns ao se comparar cultivares, por isso as discrepâncias relatadas até então. Ressalta-se ainda que abordagens que expliquem os efeitos das relações entre os nutrientes no abacaxizeiro, de modo geral são escassos, especialmente entre macro e micronutrientes, tanto que ao explorar apenas a relação K/N, Rodrigues et al. (2013) apontam dificuldades na compreensão dos resultados, expondo que esse tipo de análise no Brasil ainda é incipiente e generalista com experimentação limitada.

Apesar dos valores de alguns nutrientes estarem abaixo das faixas recomendadas para a cultura (Tabelas 3 e 4), a qualidade do abacaxi não foi prejudicada, estando os valores biométricos e a qualidade físico-química adequados a comercialização da fruta (Tabelas 5 e 6). Vilela, Pegoraro e Maia (2015), expõem que os teores de macro e micronutrientes na folha D tem baixa correlação com a massa do fruto, que é uma das respostas que interessam, pois define a produtividade do cultivo. As práticas de cobertura e o manejo de plantas daninhas também não influenciaram de maneira expressiva a qualidade dos frutos, sendo as principais diferenças atribuídas ao genótipo (Tabelas 5 e 6). O cultivo com cobertura plástica reduziu ligeiramente a firmeza e o teor de vitamina $\mathrm{C}$, enquanto o manejo químico das plantas daninhas promoveu pequena redução na circunferência dos frutos (Tabela 5).

O peso dos frutos e da coroa para o 'Pérola' são similares às descrições da literatura, estando na faixa de 1,4-1,8 kg e $100 \mathrm{~g}$ respectivamente (Reinhardt et al., 2002) já para o 'Vitória', enquanto o peso da coroa é levemente acima do exposto por Berilli et al. (2014) as respostas para peso do fruto sem a coroa são contraditórias, pois o potencial de peso do fruto da cultivar foi em média próximo de 1,5 kg (Ventura; Costa; Caetano, 2009) e os relatos descrevem pesos entre 0,900- 1,1 kg (Cardoso et al., 2013; Caetano et al., 2013), somente Amorim et al., (2011) manejando micronutrientes na cultivar Vitória produziu frutos entre 1,26-1,31 kg próximos aos descritos na tabela 5. A diferença de $110 \mathrm{~g}$ entre os cultivares aumenta quanto se pensa na produção em toneladas por hectare, havendo maior rendimento para o 'Pérola', entretanto, na exploração desta cultivar junto a 
'Smooth Cayenne' foi abordado que se feito o plantio no mesmo período e mantido condições ambientais semelhantes, a diferença de peso por fruto pode variar até entre 300 a $400 \mathrm{~g}$ (Reinhardt et al., 2002).

A firmeza dos frutos, não foi influenciada pelo tipo de manejo de plantas daninhas, e para o mulching, apesar da diferença ter sido estatisticamente significativa, os valores não chegam a afetar na tomada de decisão da comercialização dos frutos (Tabela 5). Entretanto, a resposta entre as cultivares, foi mais expressiva, havendo vantagem para o 'Vitória', pois a firmeza do fruto na pós-colheita remete à maior resistência ao manuseio, culminando em maior tempo de prateleira e menor fragilidade no transporte. Berilli et al. (2014) ao comparar a firmeza entre 'Vitória' e 'Pérola' confirmam a discrepância da firmeza, com 10,5 e 5,6 kgf respectivamente, ambos valores inferiores ao deste estudo para ambas cultivares.

Tabela 5. Peso da coroa (PC), peso do fruto (PF), firmeza (FIR), circunferência (CIR), comprimento do fruto (COM), rendimento da polpa (REN) e vitamina C (VIT C- expressa em miligrama de ácido ascórbico em $100 \mathrm{ml}$ de polpa) de frutos de abacaxizeiro Pérola e Vitória cultivados com e sem mulching e submetidos a diferentes métodos de controle de plantas daninhas. *Médias seguidas de mesmas letras minúsculas na coluna, na comparação entre os níveis dos fatores, não diferem estatisticamente pelo teste Tukey $(\mathrm{p}>0,05)$.

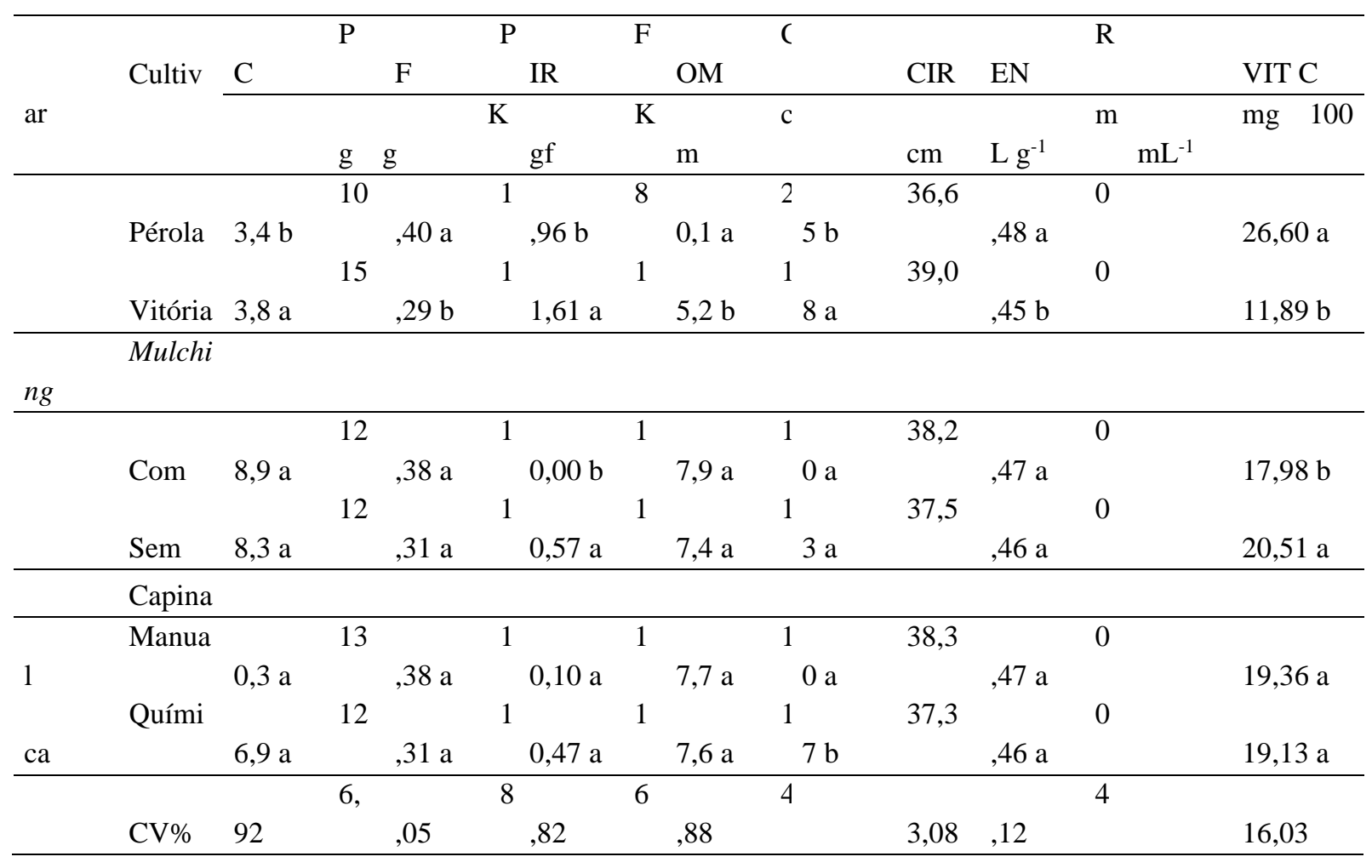

Fonte: Autores.

O comprimento de frutos foi influenciado somente pelo cultivar, com destaque para o 'Pérola', o qual atingiu em média $20 \mathrm{~cm}$, semelhante à obtida por Reinhardt et al. (2002). A média obtida para o 'Vitória' foi superior à descrita em outros trabalhos recentes para a Região Litoral Norte e com indução floral menor um mês menor (dez meses após o plantio), Barker et al. (2018) produziu frutos com $8,79 \mathrm{~cm}$, enquanto Küster et al. (2017) no cultivo sequeiro, variando o plantio em julho e setembro, obteve frutos com média de $11,51 \mathrm{~cm}$. A variação é associada às condições edafoclimáticas no plantio e indução floral, que podem influenciar significativamente na qualidade dos frutos (Galeano et al., 2016; Santos et al., 2019). A circunferência obtida para os frutos se mostrou inversamente proporcional em relação ao comprimento, sendo mais 
determinante quando se compara cultivares, embora, entre as capinas haja diferença, os valores não são decisivos no momento da venda. Valores similares foram encontrados por Barker et al. (2018).

O rendimento da polpa ficou com valores muito próximos para todos os fatores avaliados neste estudo (genótipo, uso de cobertura e tipo de capina), apresentando diferença significativa apenas entre as cultivares, na qual destaca-se o Pérola, ainda assim o rendimento alcançado foi inferior a faixa de 0,57 a $0,72 \mathrm{ml} / \mathrm{g}$ de fruto apresentados por Pereira et al. (2009), os quais mencionam ainda que esta variável pode aumentar em situações de maior disponibilidade de água durante o desenvolvimento e maturação dos frutos. No tratamento em que o solo teve a cobertura plástica e consequentemente, melhor conservação da água, o rendimento da polpa não foi tão expressivo nem interagiu com as cultivares, para elevar os valores.

Já para a vitamina $C$, os resultados apontam que o tipo de capina não influencia significativamente no teor de vitamina C na polpa de abacaxi, entretanto o cultivo sem mulching pode elevar o teor da substância, bem como o material genético, podendo-se notar uma elevação em torno de $126 \%$ de ácido ascórbico no Pérola em relação ao 'Vitória'. Para este último, os valores alcançados corroboram com Ventura et al. (2009), e apesar de ratificar a diferença entre as duas cultivares, constatadas por Berilli et al. (2014), nota-se o cultivo sem mulching desencadeou o acumulo próximo de 47\% considerando o teor de 13,94 mg de ácido ascórbico para cada $100 \mathrm{~g}$ de polpa de abacaxi 'Pérola' descrito por estes autores que também não adotaram a cobertura plástica no cultivo das plantas. Essa elevação de vitamina $C$ é interessante se partir do fato que a vitamina $C$ relaciona-se intimamente com o metabolismo antioxidante no vegetal, e a condição de cultivo sem mulching ao expor a planta a maiores flutuações de temperatura e umidade, pode desencadear eventos de estresse e consequente produção e acumulo dessa substância.

Além disso, incrementos de vitamina $\mathrm{C}$ nos frutos mostram-se importantes do ponto vista nutricional, favorecendo o comércio da fruta para o consumo in natura e comercial. Além disso, existe também uma variação da característica conforme a cultivar, estágio de maturação e propriedades edáficas, explica Marques et al. (2020). A concentração deste composto impede o desenvolvimento de alterações fisiológicas como o escurecimento interno comum no período de comercialização dos frutos. $\mathrm{O}$ uso de mulching mostrou que a cv. Pérola é indiferente na capina manual ou química para as características físico-químicas do fruto, enquanto que para a cv. Vitória, a capina química e o mulching favoreceram a expressão desses atributos, como a redução da acidez e aumento da relação SS/AT, que se correlaciona melhor com o sabor da fruta (Tabela 6).

Tabela 6. Sólidos solúveis (SS) expresso em graus Brix, de frutos abacaxi e vitória de abacaxizeiro com manejo químico e manual de plantas daninhas e acidez titulável (AT) expresso em porcentagem de ácido cítrico e relação brix/AT no cultivo com e sem mulching. *Médias com mesmas letras minúsculas na coluna e mesmas letras maiúsculas na linha não diferem estatisticamente pelo teste Tukey $(\mathrm{p}>0,05)$.

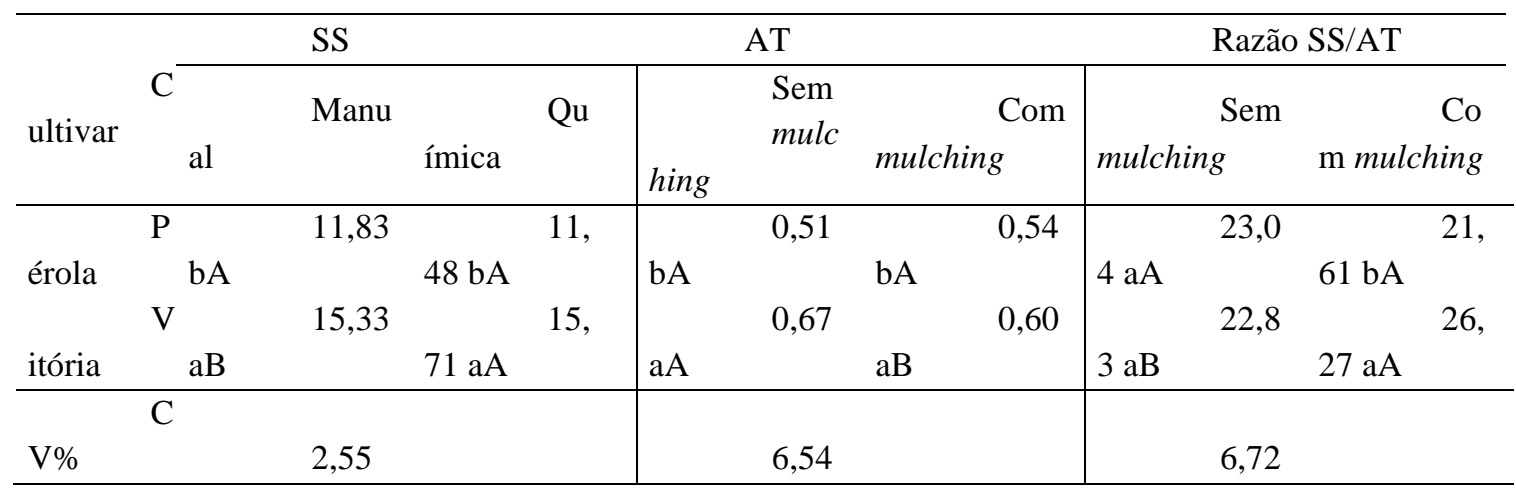

Fonte: Autores. 
A disparidade entre as cultivares em quase 23\% para sólidos solúveis é elucidada por Ventura, Costa e Caetano (2009) ao mencionarem que se comparado com o 'Pérola', o elevado valor de açúcares na polpa do 'Vitória', confere sabor agradável e aptidão dos frutos tanto para aproveitamento em agroindústria como para o consumo in natura. Testes físico-químicos realizados por Ogawa et al. (2018) em diferentes estádios de maturação de frutos da cv. Vitória mostraram uma variação de açúcares e ácidos presentes no suco com aumento nos valores de sólidos solúveis totais (SS), acidez total titulável (AT) e na relação SS/AT, em função do estágio de maturação dos frutos, onde um valor máximo foi observado no estágio 3 (3/4 do fruto está amarelo, que corresponde à cor da casca da fruta). Ao confrontar os valores de sólidos solúveis com os nutrientes no tecido foliar de cada cultivar (Tabela 4), justifica-se que a maior média para o abacaxi 'Vitória', independente do tipo de capina ou mulching, relacionam-se principalmente com ao teor de potássio em detrimento ao de nitrogênio. Sanya et al. (2020) ao testar a relação K/N no abacaxizeiro concluem que o aumento do nível de potássio favorece a qualidade dos atributos sensoriais por elevar o grau Brix, acidez titulável e vitamina $\mathrm{C}$, ao passo que o aumento do teor de nitrogênio leva a diminuição destes parâmetros.

Ao relacionar esses os aspectos químicos dos frutos em relação à altura da planta e índice SPAD, fica evidente um comportamento diferenciado das cultivares em relação ao desenvolvimento vegetativo versus qualidade dos frutos, verificou-se que o 'Vitória' produziu frutos com melhores atributos químicos, que podem ser potencializados com alterações no processo de cultivo (uso de mulching). A cultivar Pérola mostrou ter rusticidade onde o metabolismo centra-se em intensa atividade de alongamento e multiplicação, formando uma planta vigorosa e de maior porte, mas que produz frutos de baixa qualidade mesmo quando manejada a cobertura do solo. Destaca-se ainda que o cultivo sem mulching expõe a planta à evapotranspiração intensa, e a ocorrência de estresse, que de acordo com Feng et al. (2017), desencadeia mudanças na atividade enzimática do metabolismo da sacarose, reduzindo os valores.

Embora o desenvolvimento vegetativo inicial tenha sido favorecido pelo cultivo com cobertura plástica, os resultados obtidos nos frutos produzidos em cultivo com mulching e entre os tipos de capina, fortalecem a hipótese que a escolha de determinada combinação das técnicas de manejo de plantas infestantes não é determinante na produção de frutos. No entanto, a cobertura dos canteiros atenua a variação de temperatura e a capina minimiza a competição com as plantas de abacaxi, sendo importantes no desenvolvimento da planta.

\section{Conclusão}

O trabalhador rural gastou mais tempo na capina da cultivar Pérola e o mulching reduziu o tempo de capina e foi mais eficiente que o cultivo apenas com herbicida, porém quando combinado com controle químico praticamente não foi necessário efetuar o manejo das plantas daninhas.

Os tipos de capina avaliados não influenciaram no desenvolvimento vegetativo das plantas das duas cultivares de abacaxizeiro e nem na qualidade dos frutos, sendo tanto a capina química com o uso do herbicida Diuron, como a capina manual, recomendadas para a cultura.

Na cultivar Pérola, não houve efeito do uso de mulching no desenvolvimento das plantas e na qualidade dos frutos, podendo ser cultivada com ou sem mulching e com manejo químico ou manual das plantas daninhas, mostrando a sua maior rusticidade em comparação com a cv. Vitória.

O cultivo do abacaxizeiro 'Vitória' com mulching proporcionou melhor desenvolvimento vegetativo e melhoria nas características químicas dos frutos, como a redução da acidez e aumento da relação SS/AT.

A cultivar Pérola apresentou maior índice e acumulo maior dos teores de nitrogênio e de ferro nas folhas $\mathrm{D}$, com a produção de frutos com massa e comprimento superiores e circunferência menores, teores de sólidos solúveis baixo (12 $\left.{ }^{\circ} \mathrm{Brix}\right)$, maior rendimento de polpa e quase o dobro de vitamina $\mathrm{C}$ em relação ao 'Vitória'. 
A cultivar Vitória apresentou os maiores teores de potássio e magnésio nas folhas D e produziu frutos com maior firmeza de casca e teores de sólidos solúveis ( $\left.16^{\circ} \mathrm{Brix}\right)$, com acidez superior, maior rátio e sabor mais expressivo em relação ao 'Pérola'.

O cultivo do abacaxizeiro utilizando mulching teve sua eficiência demonstrada no manejo de plantas daninhas de duas importantes cultivares brasileiras e na indução do desenvolvimento vegetativo e melhoria da qualidade dos frutos da cultivar Vitória no norte capixaba. No entanto, este trabalho deve ser ampliado para mais polos produtivos e variando sistemas de manejo nutricional e hídrico, para que recomendações técnicas efetivas. Os resultados obtidos neste trabalho evidenciam que a cultivar Pérola é mais vigorosa que a Vitória, sustentando a hipótese de que as cultivares resistentes são mais dependentes de insumos, porém, são necessários mais estudos considerando um número maior de cultivares e sistemas produtivos

\section{Referências}

Acharya, C. L., Bandyopadhyay, K. K., \& Hati, K. M. (2018). Mulches: Role in climate resilient agriculture. Reference Module In Earth Systems And Environmental Sciences.

Alvares, C. A., Stape, J. L., Sentelhas, P. C., Gonçalves, J. D. M., \& Sparovek, G. (2013). Köppen's climate classification map for Brazil. Meteorologische Zeitschrift, 22(6), 711-728.

Amorim, A. V., Lacerda, C. F. D., Moura, C. F. H., \& Gomes Filho, E. (2011). Fruit size and quality of pineapples cv. Vitória in response to micronutrient doses and way of application and to soil covers. Revista Brasileira de Fruticultura, 33(SPE1), 505-510.

Aquije, G. M. D. F. V., Zorzal, P. B., Buss, D. S., Ventura, J. A., Fernandes, P. M. B., \& Fernandes, A. A. R. (2010). Cell wall alterations in the leaves of fusariosis-resistant and susceptible pineapple cultivars. Plant Cell Reports, 29(10), 1109-1117.

Araújo, P. (2019). Crise hídrica na área da Sudene no Espírito Santo: um limitador do potencial da produção de café Conilon. Dissertação de mestrado. Faculdade Vale do Cricaré, São Mateus, ES, Brasil.

Barbosa, F. E., Lacerda, C. F. D., Feitosa, H. D. O., Soares, I., Andrade Filho, F. L. D., \& Amorim, A. V. (2013). Crescimento, nutrição e produção da bananeira associados a plantas de cobertura e lâminas de irrigação. Revista Brasileira de Engenharia Agrícola e Ambiental, 17(12), 1271 -1277.

Barker, D. L., Arantes, S. D., Schmildt, E. R., Arantes, L. D. O., Fontes, P. S. F., \& Buffon, S. B. (2018). Post-harvest quality of 'Vitória’pineapple as a function of the types of shoots and age of the plant for floral induction. Revista Brasileira de Fruticultura, 40(4).

Berilli, S. D. S., Freitas, S. D. J., Santos, P. C. D., Oliveira, J. G. D., \& Caetano, L. C. S. (2014). Avaliação da qualidade de frutos de quatro genótipos de abacaxi para consumo in natura. Revista Brasileira de Fruticultura, 36(2), 503-508.

Caetano, L., \& Ventura, J. A. (2018). Viveiro de mudas micropropagadas de abacaxizeiro. (2a ed.).

Caetano, L. C. S., Ventura, J. A., Costa, A. D. F. S. D., \& Guarçoni, R. C. (2013). Efeito da adubação com nitrogênio, fósforo e potássio no desenvolvimento, na produção e na qualidade de frutos do abacaxi'Vitória'. Revista Brasileira de Fruticultura, 35(3), 883-890.

Cardoso, M. M., Pegoraro, R. F., Maia, V. M., Kondo, M. K., \& Fernandes, L. A. (2013). Crescimento do abacaxizeiro'Vitória'irrigado sob diferentes densidades populacionais, fontes e doses de nitrogênio. Revista Brasileira de Fruticultura, 35(3), $769-781$.

Catunda, M. G., Freitas, S. P., Oliveira, J. G., \& Silva, C. M. M. (2005). Efeitos de herbicidas na atividade fotossintética e no crescimento de abacaxi (Ananas comossus). Planta daninha, 23(1), 115-121.

Couto, T. R., Silva, J. R., Moraes, C. R. O., Ribeiro, M. S., Netto, A. T., Carvalho, V. S., \& Campostrini, E. (2016). Photosynthetic metabolism and growth of pineapple (Ananas comosus L. Merr.) cultivated ex vitro. Theoretical and Experimental Plant Physiology, 3(28), 333-339.

FAO (2020). Medium-term Outlook: Prospects for global production and trade in bananas and tropical fruits 2019 to 2028 . Rome.

Outlook, F. M. T. (2020). Prospects for Global Production and Trade in Bananas and Tropical Fruits 2019 to 2028 . Food and Agriculture Organization of the United Nations: Rome, Italy.

Feng, H., Du, L., Liu, S., \& Zhang, X. (2017). Effects of different deficit irrigation on sugar accumulation of pineapple during development. Earth and Environmental Science 81(1), 1-7.

Ferreira, D. F. (2011). Sisvar: a computer statistical analysis system. Ciência e agrotecnologia, 35, 1039-1042.

Galeano, E. A. V., Maso, L.J., Costa, A. F. S., Taques, R. C., Ferrão, R. G. (2011) Estimativa de perdas na produção agrícola capixaba em 2015. Incaper em Revista, 6e7(4), 26-41.

Guarçoni, A., Favarato, L. F., Stipp, S. R., Casarin, V. (2019) Manejo da fertilidade do solo para uma produção agropecuária mais sustentável. Incaper em Revista, 10, 22-42.

I. A. L., Instituto Adolfo Lutz (2008). Métodos físico-químicos para análise de alimentos. (4aed.) Brasília DF 
IBGE-Instituto Brasileiro De Geografia E Estatística. (2020). Produção Agrícola Municipal: PAM 2019. Sistema IBGE de Recuperação Automática: SIDRA. <https://bit.ly/2IUNLA1/>

IBGE-Instituto Brasileiro De Geografia E Estatística. (2020). Censo Agropecuário 2017.: < https://censos.ibge.gov.br/agro/2017/>

Kist, H. G. K., Ramos, J. D., Santos, V. A. D., \& Rufini, J. C. M. (2011). Fenologia e escalonamento da produção do abacaxizeiro'Smooth Cayenne'no Cerrado de Mato Grosso. Pesquisa Agropecuária Brasileira, 46, 992-997.

Küster, I. S., Alexandre, R. S., Arantes, S. D., Schmildt, E. R., Arantes, L. D. O., Bonomo, R., \& Klem, D. L. B. (2017). Influência da época de plantio e indução floral na qualidade de frutos de abacaxi 'Vitória'. Revista Ifes Ciência, 3(2), 29-53.

Leonardo, F. D. A. P., Pereira, W. E., Silva, S. D. M., \& Costa, J. P. D. (2013). Teor de clorofila e índice SPAD no abacaxizeiro cv. Vitória em função da adubação nitrogenada. Revista Brasileira de Fruticultura, 35(2), 377-383.

Maia, V. M., Pegoraro, R. F., Aspiazú, I., Oliveira, F. S., \& Nobre, D. A. C. (2020). Diagnosis and management of nutrient constraints in pineapple. In Fruit Crops (pp. 739-760).

Malavolta, E. (1982) O potássio e a planta. (4a ed.). Instituto da Potassa. Boletim Técnico

Malavolta, E. (1997). Avaliação do estado nutricional das plantas: princípios e aplicações/Eurípedes Malavolta, Godofredo Cesar Vitti, Sebastião Alberto de Oliveira. (2॰ ed.). Piracicaba: Potafos.

Malézieux, E., \& Bartholomew, D. P. (2003) Plant nutrition. In: Bartholomew, D. P., Paul, R. E., \& Rohrbach, K. G. (Ed.). The pineapple: botany, production and uses. Honolulu. 143-165.

Marques, D. D., de Menezes, R. S. A., Sartori, R. A., de Carvalho, C. E. G., \& Rogez, H. L. G. (2020). Análises física e físico-química de duas cultivares de abacaxi do estado do Acre: Gigante-de-Tarauacá e Rio Branco. Brazilian Journal of Development, 6(4), 16665-16674.

MAPA. (2020). Relação dos padrões oficiais estabelecidos pelo Ministério da Agricultura, Pecuária e Abastecimento para a classificação. Atualizado em 03.03.2017. http://www.agricultura.gov.br/assuntos/inspecao/produtosvegetal/arquivos/RELAODOSPR ODUTOSPADRONIZADOS03032017.pdf.

Mello, C. R. D., Viola, M. R., Curi, N., \& Silva, A. M. D. (2012). Distribuição espacial da precipitação e da erosividade da chuva mensal e anual no Estado do Espírito Santo. Revista Brasileira de Ciência do Solo, 36(6), 1878-1891.

Model, N. S., \& Favreto, R. (2010). Comparação de custos de tratamentos de controle de plantas daninhas em abacaxizeiro cultivado no Rio Grande do Sul, Brasil. Pesquisa Agropecuária Gaúcha, 16(1/2), 45-50.

Model, N. S., Favreto, R., \& Rodrigues, A. E. C. (2010). Efeito de tratamentos de controle de plantas daninhas sobre produtividade, sanidade e qualidade de abacaxi. Pesquisa Agropecuária Gaúcha, 16(1/2), 51-58.

Mógor, Á. F., \& Câmara, F. L. A. (2009). Cobertura do solo, produção de biomassa e teores de Mn e Zn de alface no sistema orgânico. Acta Scientiarum. Agronomy, 31(4), 621-626.

Ogawa, E. M., Costa, H. B., Ventura, J. A., Caetano, L. C., Pinto, F. E., Oliveira, B. G., Barroso, M. E. S., Scherer, R., Endringer, D. C \& Romão, W. (2018). Chemical profile of pineapple cv. Vitória in different maturation stages using electrospray ionization mass spectrometry. Journal of the Science of Food and Agriculture, 98(3), 1105-1116.

O'loughlin, J., Finnan, J., \& Mcdonnell, K. (2017). Accelerating early growth in miscanthus with the application of plastic mulch film. Biomass and Bioenergy, 100, 52-61.

Pegoraro, R. F., Souza, B. A. M. D., Maia, V. M., Silva, D. F. D., Medeiros, A. C., \& Sampaio, R. A. (2014). Macronutrient uptake, accumulation and export by the irrigated'vitória'pineapple plant. Revista Brasileira de Ciência do Solo, 38(3), 896-904.

Pereira, M. A. B., Siebeneichler, S. C., Lorençoni, R., Adorian, G. C., Silva, J. C. D., Garcia, R. B. M., Pequeno, D. N. L., Souza, C. M. \& Brito, R. F. F. D. (2009). Qualidade do fruto de abacaxi comercializado pela Cooperfruto: Miranorte-TO. Revista Brasileira de Fruticultura, 31 , $1049-1053$.

Pezzopane, J. E. M., Santos, E. A., Eleutério, M. M., Reis, E. D., \& Santos, A. D. (2004). Espacialização da temperatura do ar no Estado do Espírito Santo. Revista Brasileira de Agrometeorologia, 12(1), 151-158.

Prezotti, L. C., Oliveira, J. A., Gomes, J. A., \& Dadalto, G. G. (2013). Manual de recomendação de calagem e adubação para o Estado do Espírito Santo: $5^{\text {a }}$ aproximação.

Rebolledo Martinez, A., Pérez, A. L. Del A., Román, A. E. B., \& Rebolledo Martinez, L. (2005). Growth analysis for three pineapple cultivars grown on plastic mulch and bare soil. Interciencia, 30(12), 758-763.

Reinhardt, D. H., Cabral, J. R. S., da Silva Souza, L. F., Sanches, N. F., \& De Matos, A. P. (2002). Pérola and Smooth Cayenne pineapple cultivars in the state of Bahia, Brazil: growth, flowering, pests, diseases, yield and fruit quality aspects. Fruits, 57(1), 43-53.

Reinhardt, D. H. R., Bartholomew, D. P., Souza, F. V. D., Carvalho, A. C. P. P. D., Pádua, T. R. P. D., Junghans, D. T., \& Matos, A. P. D. (2018). Advances in pineapple plant propagation. Revista Brasileira de Fruticultura, 40(6).

Rodrigues, A. A., Mendonça, R. M. N., Silva, A. P. D., \& Silva, S. D. M. (2013). Nutrição mineral e produção de abacaxizeiro'Pérola', em função das relações K/N na adubação. Revista Brasileira de Fruticultura, 35(2), 625-633.

Sampaio, R. A., \& Araújo, W. F. (2001). Importância da cobertura plástica do solo sobre o cultivo de hortaliças. Agropecuária Técnica, 22(1/2), 1-12. 
Research, Society and Development, v. 10, n. 13, e449101321520, 2021

(CC BY 4.0) | ISSN 2525-3409 | DOI: http://dx.doi.org/10.33448/rsd-v10i13.21520

Santos, R. B. D., Menezes, J. A., Confalonieri, U., Madureira, A. P., Duval, I. D. B., Garcia, P. P., \& Margonari, C. (2019). Construção e aplicação de um índice de vulnerabilidade humana à mudança do clima para o contexto brasileiro: a experiência do estado do Espírito Santo1. Saúde e Sociedade, 28(1), 299321 .

Sanya, C. A., Chadare, F. J., Hounhouigan, M. H., Hotegni, N. V. F., Gbaguidi, M. A., Dekpemadoha, J. E., Linnemann, A. R., \& Hounhouigan, D. J. (2020). Effects of plant density and fertilizer formula on physicochemical and sensorial characteristics of pasteurized juice from Perolera sugarloaf pineapples grown in the long rainy season. NJAS-Wageningen Journal of Life Sciences, 92, 100320.

Siebeneichler, Susana Cristine et al. Boro em abacaxizeiro'Pérola'no norte fluminense: teores, distribuição e características do fruto. Revista Brasileira de Fruticultura, 30(3), 787-793, 2008.

Silva, A. L. P. D., Silva, A. P. D., Souza, A. P. D., Santos, D., Silva, S. D. M., \& Silva, V. B. D. (2012). Resposta do abacaxizeiro'Vitória'a doses de nitrogênio em solos de tabuleiros costeiros da Paraíba. Revista Brasileira de Ciência do Solo, 36(2), 447-456.

Silva, R. P., Favreto, R., Bertoldo, J. G., Abichequer, A. D., Tonietto, A., \& Santin, A. (2020). Alternativas para o controle de plantas espontâneas no cultivo do abacaxizeiro. Pesquisa Agropecuária Gaúcha, 26(1), 55-67.

Souza, L. D. S., \& de Almeida, O. A. (2002). Requerimento de nutrientes para fertirrigação. 1. Abacaxi Borges, A. L, Coelho, E. F., \& Trindade, A. V. Fertirrigação em fruteiras tropicais, 68-76.

Souza, O. P. D., Teodoro, R. E. F., Melo, B. D., \& Torres, J. L. R. (2009). Qualidade do fruto e produtividade do abacaxizeiro em diferentes densidades de plantio e lâminas de irrigação. Pesquisa Agropecuária Brasileira, 44(5), 471-477.

Taiz, L., Zeiger, E., Møller, I. M., \& Murphy, A. (2017). Fisiologia e desenvolvimento vegetal. Artmed Editora.

Uliana, E. M., dos Reis, E. F., da Silva, J. G. F., \& Xavier, A. C. (2013). Precipitação mensal e anual provável para o Estado do Espírito Santo. Irriga, 18(1), $139-417$.

Veloso, C. A. C., Oeiras, A. H. L., Carvalho, E. J., \& Souza, F. R. (2001). Resposta do abacaxizeiro à adição de nitrogênio, potássio e calcário em latossolo amarelo do nordeste paraense. Revista Brasileira de Fruticultura, 23(2), 396-402.

Venâncio, J. B., Araújo, W. F., Chagas, E. A., \& Melo, R. S. (2017). Teores e extração de macronutrientes pelas folhas do abacaxizeiro 'Vitória' sob adubação potássica e lâminas de irrigação. Irriga, 22(2), 400-419.

Ventura, J. A., Costa, H., \& Caetano, L. C. S. (2009). Abacaxi'vitória': uma cultivar resistente à fusariose. Revista Brasileira de Fruticultura, 31 (4), 1-2.

Vieira, D. A. D. P., Portes, T. D. A., Stacciarini-Seraphin, E., \& Teixeira, J. B. (2010). Fluorescência e teores de clorofilas em abacaxizeiro cv. Pérola submetido a diferentes concentrações de sulfato de amônio. Revista Brasileira de Fruticultura, 32(2), 360-368.

Vilela, G. B., Pegoraro, R. F., \& Maia, V. M. (2015). Predicting the production of' Vitória' pineapple from phytotechnical and nutritional characteristics. Revista Ciência Agronômica, 46(4), 724-732. 